The University of Maine

\title{
DigitalCommons@UMaine
}

Earth Science Faculty Scholarship

Earth Sciences

9-1-2004

\section{Basal Melting Along the Floating Part of Byrd Glacier}

James P. Kenneally

Terence J. Hughes

University of Maine - Main, terry.hughes@maine.edu

Follow this and additional works at: https://digitalcommons.library.umaine.edu/ers_facpub

Part of the Earth Sciences Commons

\section{Repository Citation}

Kenneally, James P. and Hughes, Terence J., "Basal Melting Along the Floating Part of Byrd Glacier" (2004). Earth Science Faculty Scholarship. 15.

https://digitalcommons.library.umaine.edu/ers_facpub/15

This Article is brought to you for free and open access by DigitalCommons@UMaine. It has been accepted for inclusion in Earth Science Faculty Scholarship by an authorized administrator of DigitalCommons@UMaine. For more information, please contact um.library.technical.services@maine.edu. 


\title{
Basal melting along the floating part of Byrd Glacier
}

\author{
JAMES P. KENNEALLY ${ }^{1}$ and TERENCE J. HUGHES ${ }^{2}$ \\ ${ }^{1}$ Department of Physics, Climate Change Institute, University of Maine, Orono, ME 04469-5790, USA \\ ${ }^{2}$ Department of Earth Sciences, Climate Change Institute, University of Maine, Orono, ME 04469-5790, USA
}

\begin{abstract}
A mass balance calculation was made for the floating part of Byrd Glacier, using 1978-79 ice elevation and velocity data, over the $45 \mathrm{~km}$ of Byrd Glacier from its grounding line to where it leaves its fjord and merges with the Ross Ice Shelf. Smoothed basal melting rates were relatively uniform over this distance and averaged $12 \pm 2 \mathrm{~m} \mathrm{yr}^{-1}$.
\end{abstract}

Received 6 January 2004, accepted 18 May 2004

Key words: Antarctic Ice Sheet, grounding line, mass balance, Ross Ice Shelf

\section{Introduction}

Byrd Glacier is an outlet glacier, located in a fjord through the Transantarctic Mountains (Fig. 1). It supplies ice from the East Antarctic Ice Sheet to the Ross Ice Shelf, and becomes afloat halfway through the fjord (Hughes \& Fastook 1981). Brecher (1982) measured 1003 elevations and 471 velocities on Byrd Glacier at sites shown in Fig. 2,

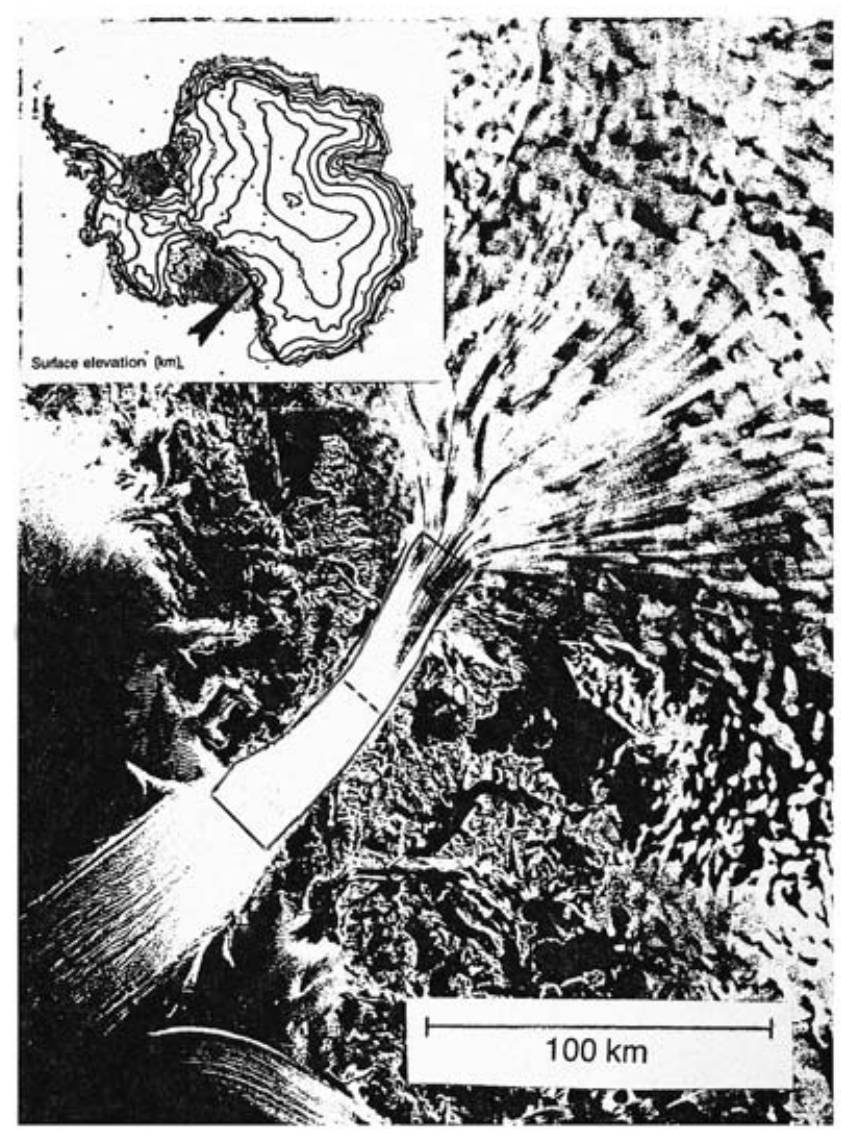

Fig. 1. Byrd Glacier and its flowband on the Ross Ice Shelf. Inset map shows location. From Jezek (1998). The data box in Fig. 2 is shown undistorted between the fjord walls of Byrd Glacier. The dashed line marks the grounding line for this study. using photogrammetric triangulation from two sets of aerial photography in December 1978 and January 1979. Using these data, mass losses or gains to the floating part of Byrd Glacier can be determined by a conservation of mass calculation.

\section{Locating the grounding line}

A reasonable location of the grounding line is needed to begin a conservation of mass calculation for the floating part of Byrd Glacier. Byrd Glacier has a grounding zone that migrates with the tide, rather than a stationary grounding line (Hughes \& Fastook 1981). A single grounding line needs to be specified in a mass balance calculation. A simple way to do this is to determine changes in ice velocity and elevation as floating ice becomes grounded. Data at sites shown in Fig. 2 are broken into data slices essentially perpendicular to the flow. Average quantities for velocity and elevation are then determined for each slice.

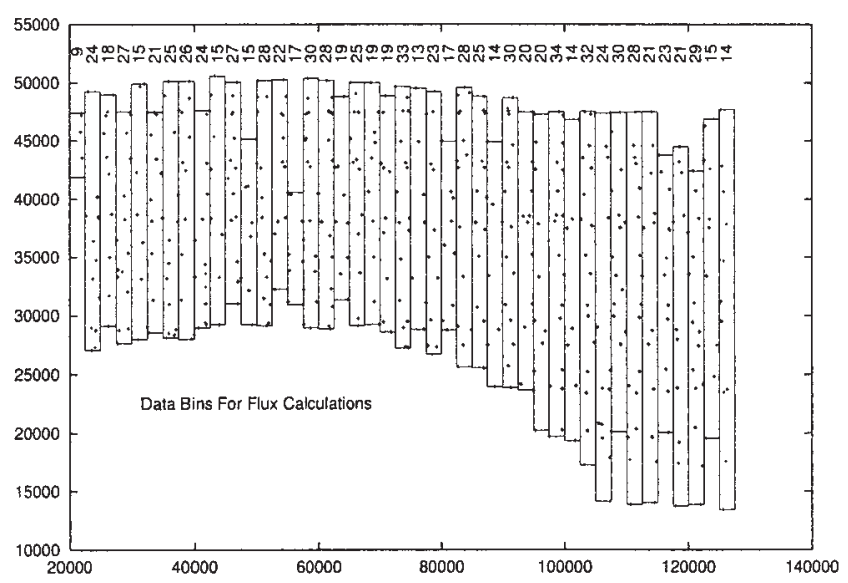

Fig. 2. Data slices created for calculating the average profile values of velocity and elevation data from Brecher (1982). The numbers across the top of each bin represent the number of elevation measurements located within that slice. Each slice is $2500 \mathrm{~m}$ wide and flow is to the right. 

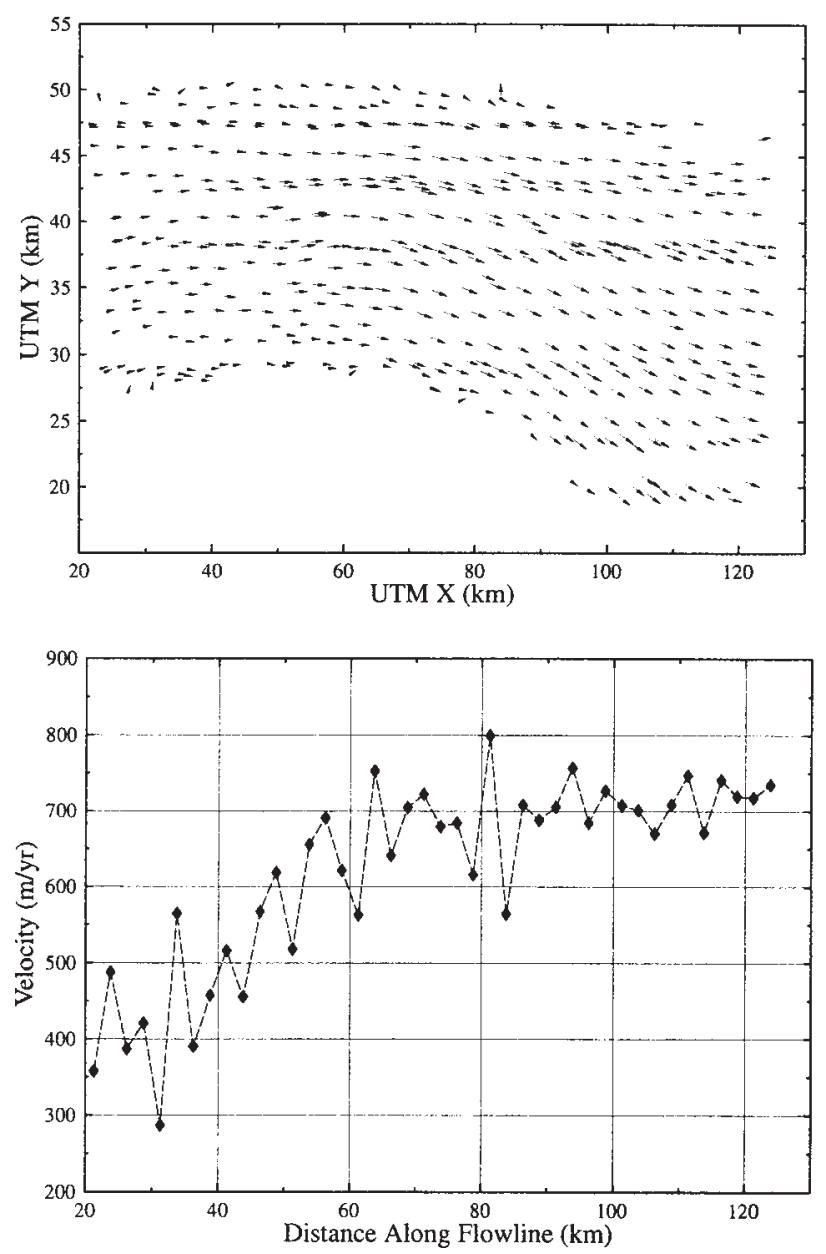

Fig. 3. Calculated velocity data for Byrd Glacier. Top = velocity vectors. Bottom $=$ average velocity profile. The velocity approaches a nearly constant value at points downstream from $x=80 \mathrm{~km}$. The UTM (Universal Transverse Mercator) X-Y coordinate grid for Byrd Glacier and the velocity vectors are from Brecher (1982).

Velocity data are rather uniformly distributed, so measurements lying within a single slice are averaged to get an average velocity for each slice. Because of the confines of the fjord walls, the motion of the ice is almost entirely longitudinal, with divergence only occurring near the entrance to the ice shelf, as seen by velocity vectors in Fig. 3 (top). The average longitudinal velocity profile is shown in Fig. 3 (bottom). Surface ice velocity becomes relatively constant at about $70 \mathrm{~km}$ to $80 \mathrm{~km}$ beyond the upslope fjord entrance.

The elevation profile is found using the same strips in Fig. 2. As with ice velocities, ice elevations are averaged in each strip because the distribution of data is uniform. Results are shown in Fig. 4. The surface slope changes sharply somewhere in the region $70 \mathrm{~km}<x<75 \mathrm{~km}$ beyond the upslope fjord entrance. A single location for the grounding line is taken as the intersection of two straight lines giving a least-squares fit to the slowly and rapidly

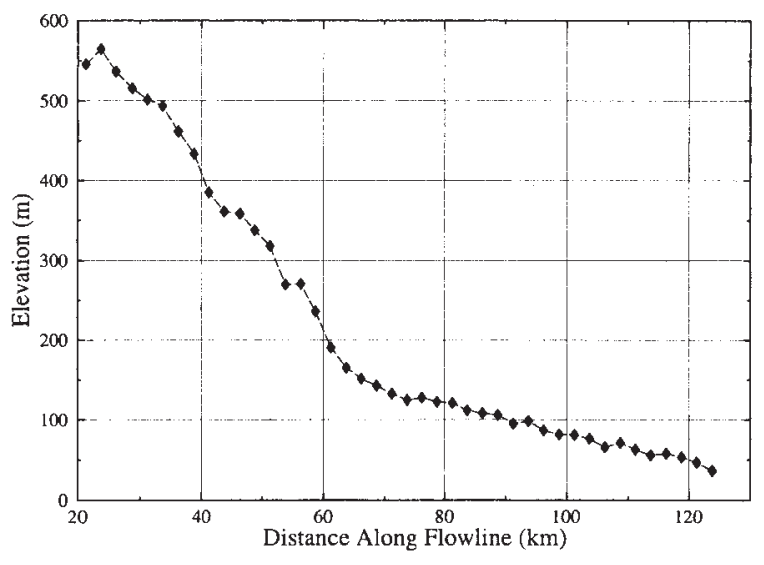

Fig. 4. Average elevation profile for Byrd Glacier.

rising ice elevation data. This gives a strip-averaged location for the grounding line. In order to detect any trend that is occurring within the data, a smoothing algorithm called a moving average is employed. The moving average is used to find trends in noisy data, and is defined as follows: Given a sequence of numbers

$$
\{a\}_{i=1}^{N}
$$

the $n$-moving average is a new sequence

$$
\{s\}_{i=1}^{N-n+1}
$$

defined from the $a$ by taking an average of subsequences of $n$ terms:

$$
s_{i}=\frac{1}{n} \sum_{j=i}^{i+n-1} a_{j}
$$

As an example, consider the 3-moving average. In this case, Fig. 1 will give a new data set $s$ :

$$
s=\frac{1}{3}\left(a_{1}+a_{2}+a_{3}, a_{2}+a_{3}+a_{4}, \ldots, a_{N-2}+a_{N-1}+a_{N}\right)
$$

where $N$ is the total number of data points.

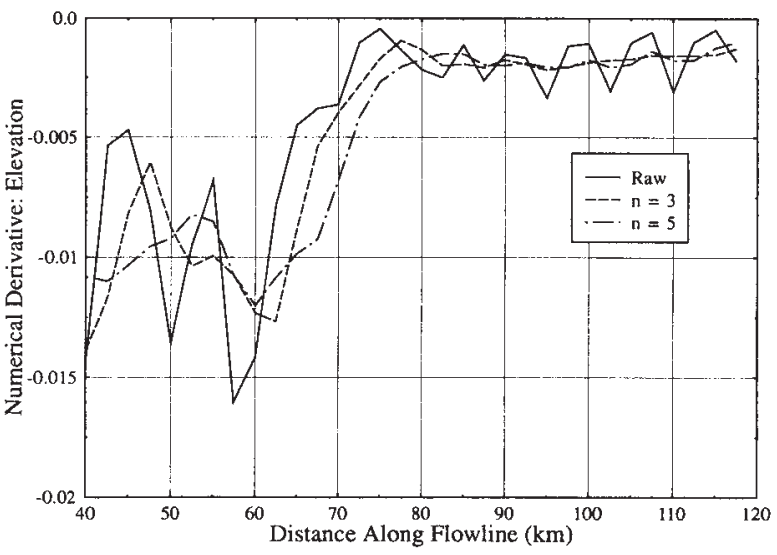

Fig. 5. Smoothed data representing the derivative of surface slope. The data converge to a stable and nearly zero value at $x=80 \mathrm{~km}$. 


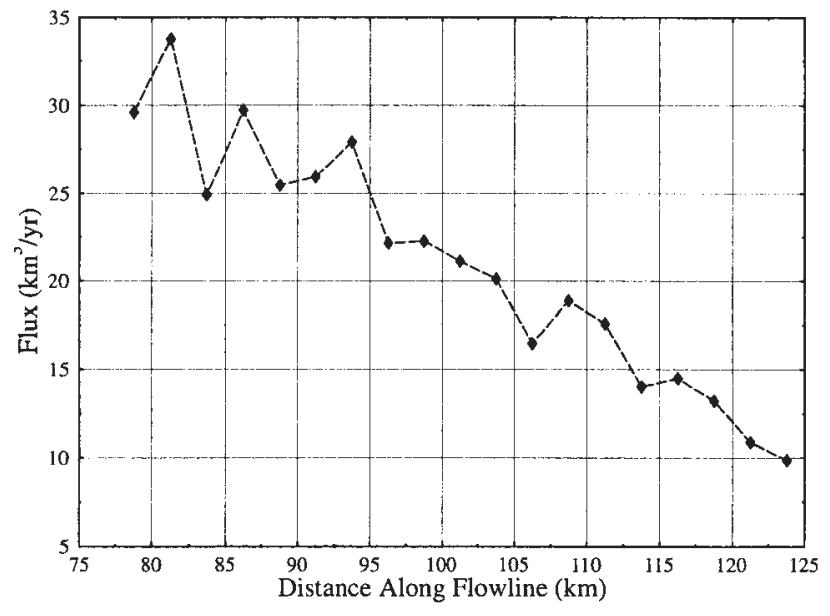

Fig. 6. Flux in $\mathrm{km} \mathrm{yr}^{-3}$ for the floating part of Byrd Glacier. The flux is decreasing along the flowline profile, indicating mass loss.

Results found by smoothing the derivative data using a moving average with $n$ equal to 3 and 5 are shown in Fig. 5, along with the unsmoothed derivative data. Derivatives for smoothed and unsmoothed data all approach a constant and nearly zero value at approximately $x=80 \mathrm{~km}$. Using results from analysing both the velocity and elevation data, the approximate grounding line for use in subsequent calculations is located at $x_{g}=80 \mathrm{~km}$ beyond the upslope fjord entrance.

\section{Calculating the ice flux}

With a determination of the grounding line, it is now possible to find the mass balance for the floating portion of Byrd Glacier using an ice flux calculation. Ice thickness $H$ was obtained from ice elevation $h$ above water using the buoyancy requirement. Ice that flows across the grounding line loses contact with the bed, so the measured surface ice velocity is also the basal ice velocity. The initial flux of ice, $\Phi_{o}$, at the grounding line will either remain the same at later points, or increase for a gain of mass, or decrease for a loss of mass. The rate of mass loss or gain is obtained from the flux conservation calculation.

The flux through a data slice in Fig. 2 is defined as a vector dot product:

$$
\Phi=\vec{A} \bullet \vec{v}
$$

where $\vec{A}$ is the vertical cross-sectional area of the slice and $\vec{v}$ is the average velocity of ice through that area. The orientation of the slice and the direction of flow at various points in the slice may not necessarily be perpendicular to one another so the dot product is used to obtain the component of flow that is normal to $\vec{A}$, with an outward unit normal vector $\hat{n}$ defined such that $\vec{v}=v \hat{n}$. Given flow vectors shown in Fig. 3 (top), velocity and area are very nearly perpendicular throughout the flow. The flux for the $i^{\text {th }}$ data slice from the grounding line on is then calculated as:

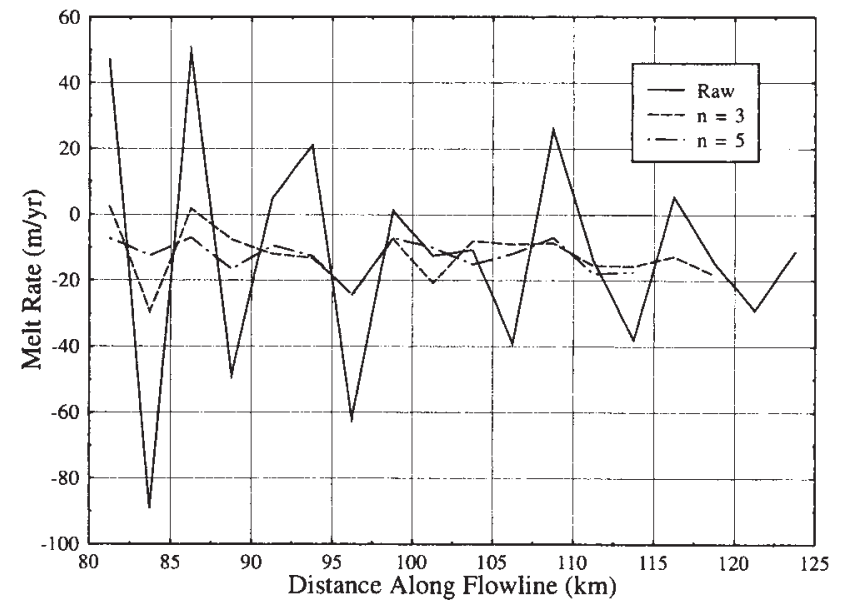

Fig. 7. Raw and smoothed melt rates $\dot{m}$ using Eq. (5) for consecutive data slices in Fig. 2. An overall average is taken for each smoothed melt rate using Eq. (1) for $n=3$ and $n=5$ to see where $\dot{m}$ converges.

$$
\Phi_{i}=W_{i}\langle H\rangle_{i}\langle v\rangle_{i}
$$

where $\langle H\rangle$ and $\langle v\rangle$ are average values of ice thickness $H$ and velocity $v$ taken from the profile calculations done earlier and $W_{i}$ is taken as the maximum extent of the data coverage in the transverse $y$-direction for the $i^{\text {th }}$ slice. The flux averaged through each floating slice is plotted in Fig. 6 for all slices.

\section{Determining basal melting rates}

Once a calculation of the flux through a given slice is made, it must be determined if the flux has been conserved between slice $i$ and $i+1$. If they are not equal, ice mass has been added or removed from the system from an outside source. A negative mass balance indicates net loss of ice by melting.

Ignoring the surface mass balance, as the flux changes from slice $i$ to slice $i+1$, the basal melt rate is found by taking the difference in fluxes and dividing by the horizontal surface area $W \Delta x$ between the slices for slices of width $W$ and longitudinal thickness $\Delta x$ :

$$
\dot{m}_{i+1}=\frac{\Phi_{i+1}-\Phi_{i}}{W_{i+1} \Delta x}
$$

Melt rates along the floating portion are shown in Fig. 7. These rates are wildly erratic, with extreme points ranging from $-90 \mathrm{~m} \mathrm{yr}^{-1}$ to $50 \mathrm{~m} \mathrm{yr}^{-1}$. These extreme points are located nearest to the assumed grounding line. Calculated melt rates tend to smooth out farther downstream. An overall melt rate, found by simply averaging the results, yields $\langle\dot{m}\rangle=11.8 \mathrm{~m} \mathrm{yr}^{-1}$. A moving average is once again employed using values of $n$ equal to 3 and 5 to smooth the melt rates so they reflect basal melting rates more accurately. Fig. 7 compares raw basal melting rates along 
the floating length of Byrd Glacier with smoothed basal melting rates calculated for $n=3$ and $n=5$. Smoothing eliminates regions of basal freezing. This high basal melting rate gives an ice loss about half of the ice discharge flux leaving the fjord and entering the Ross Ice Shelf. Therefore the ice shelf buttressing stress calculated by Reusch \& Hughes (2003) should be based on their eq. (2) rather than their eq. (8), which ignored basal melting.

\section{Error analysis}

Ice thickness $H$ was determined from ice elevations $h$ above sea level, ice densities $\rho_{I}$, and water density $\rho_{\mathrm{W}}$ through the buoyancy relationship:

$$
h=H\left(1-\rho_{I} / \rho_{W}\right)
$$

Brecher (1982) measured $h$ photogrammetrically to an accuracy of $0.8 \mathrm{~m}$ in planimetry and $1.8 \mathrm{~m}$ in elevation. One-metre ice cores were taken at most of 71 sites on the ice for measuring density and planting mass-balance poles, see Hughes (1979) for locations. Floating ice was near maximum density, $917 \mathrm{~kg} \mathrm{~m}^{-3}$, between the fjord walls due to surface ablation by katabatic winds. In two midsummer months, ablation rates at these sites increased from $0.1 \mathrm{~m}$ to $0.2 \mathrm{~m}$ down the fjord. Ice crossing the grounding line was broken into tabular "plateaus" a few tens of metres across and separated by crevasses about $30 \mathrm{~m}$ deep. The larger "plateaus" had become isolated "peaks" as ice left the fjord, suggesting some $30 \mathrm{~m}$ of ablation over a distance of $45 \mathrm{~km}$ in ice averaging $700 \mathrm{~m} \mathrm{yr}^{-1}$, giving a timespan of about 64 years, over which the average ablation rate was $0.47 \mathrm{~m} \mathrm{yr}^{-1}$. Brecher (1982) estimated a 5\% uncertainty in his velocity measurements. When combined with the scatter of $0.10 \pm$ $0.02 \mathrm{~m} / \mathrm{mo}$ for midsummer ablation rates for nearby sites in the lower fjord, and our crude measure of ablation over the 64 year period, we claim an accuracy of no better than $40 \%$ for surface ablation rates, or $0.5 \pm 0.1 \mathrm{~m} \mathrm{yr}^{-1}$.

Our calculated basal melting rates are less problematic. In Eqs (1) \& (2), the greatest uncertainty is the location of the grounding line, which is actually a grounding zone with a portion of the $0.7 \mathrm{~m}$ tidal amplitude recorded over a span of $20 \mathrm{~km}$ (Hughes \& Fastook 1981). Figure 5 suggests an uncertainty of $5 \mathrm{~km}$ averaged along the grounding line, which serves the purpose of this study. For each slice of ice shown in Fig. 2, width $W$ and length $\Delta x$ are specified, thickness $H$ is accurate to $18 \mathrm{~m}$ computed from Eq. (6) for $h$ accurate to $1.8 \mathrm{~m}$, and ice velocity across $W$ is accurate to 3\% (Brecher 1982). Equations (4) \& (5) then give a maximum error in $\dot{m}$ of about $5 \%$ for the thickest ice, increasing to $10 \%$ for the thinnest ice. However, Fig. 3 suggests a $10 \%$ velocity error for floating ice, equivalent to an error in $\dot{m}$ of $15 \%$ (thick ice) to $30 \%$ (thin ice). This is more consistent with the wide swings of $\dot{m}$ in Fig. 7, although the swings are greater for thicker ice. Therefore it is possible that basal melting rates are highly variable.

\section{Conclusions}

An average basal melt rate on the order of

$$
\langle\dot{m}\rangle \approx 12 \pm 2 \mathrm{~m} \mathrm{yr}^{-1}
$$

was calculated for the floating portion of Byrd Glacier, compared to $0.5 \pm 0.1 \mathrm{~m} \mathrm{yr}^{-1}$ for surface ablation, in 1978-79. Within the uncertainty, this agrees with $15 \pm 4 \mathrm{~m}$ $\mathrm{yr}^{-1}$ measured by Rignot \& Jacobs (2002) using velocity data taken in 1997, while allowing for increasing basal melting over those two decades. The floating part of Thwaites Glacier (Rignot 2001) and many other floating ice streams and ice shelves have similarly high basal melt rates in Antarctica (Rignot \& Jacobs 2002). If it is a recent phenomenon, prolonged rapid basal melting will lead to grounding-line retreat and downdraw of marine portions of the Antarctic Ice Sheet. This seems to be happening in West Antarctica (Shepherd et al. 2001, Zwally et al. 2002). Whether this will also occur in East Antarctica is unclear, but the Byrd Glacier grounding line may be retreating toward the headwall of its fjord (Reusch \& Hughes 2003). Although not seen clearly in Fig. 1, radarsat imagery indicates that Byrd Glacier has eroded away much of the headwall (Jezek 1998). In that case, the grounding line might be able to retreat into interior East Antarctica and allow downdraw comparable to that now associated with Lambert Glacier (Denton \& Hughes 2002).

\section{Acknowledgements}

We thank Eric Rignot and Ralph Greve for reviews that greatly improved and clarified our original manuscript.

\section{References}

BRECHER, H.H. 1982. Photographic determination of surface velocities and elevations on Byrd Glacier. Antarctic Journal of the United States, 17(5), 79-81.

Denton, G.H. \& Hughes, T.J. 2002. Reconstructing the Antarctic Ice Sheet at the Last Glacial Maximum. Quaternary Sciences Reviews, 21, 193-202.

Hughes, T. 1979. Byrd Glacier. Antarctic Journal of the United States, 14(5), 88-91.

Hughes, T.J. \& FASTOOK, J.L. 1981. Byrd Glacier: 1978-1979 field results. Antarctic Journal of the United States, 16(5), 86-89.

JeZeK, K.C., ed. 1998. Early results from the first Radarsat-1 Antarctic mapping mission. Byrd Polar Research Center Technical Report No. 9802. Columbus, $\mathrm{OH}$ : Byrd Polar Research Center, $22 \mathrm{pp}$.

Reusch, D. \& Hughes, T.J. 2003. Surface "waves" on Byrd Glacier. Antarctic Science, 16, 547-555.

RignOT, E.J. 2001. Evidence for rapid retreat and mass loss of Thwaites Glacier, West Antarctica. Journal of Glaciology, 47, 213-222.

RigNOT, E.J. \& JACOBS, S.S. 2002. Rapid bottom melting widespread near Antarctic Ice Sheet grounding lines. Science, 296, 2020-2023.

Shepherd, A., Wingham, D.J., Mansley, J.A.D. \& Corr, H.F.J. 2001. Inland thinning of Pine Island Glacier, West Antarctica. Science, 291, 862-864.

Zwally, H.J., Schultz, B., Abdalati, W., Abshire, J., Bentley, C.R., Brenner, A., Quinn, K., PAlm, S., Spinhirne, J. \& Thomas, R.H. 2002. ICESat's laser measurements of polar ice, atmosphere, ocean, and land. Journal of Geodynamics, 34, 405-445. 